\title{
Pembuahan Jeruk Siam (Citrus microcarpa L.) di Luar Musim dengan Perlakuan Induksi Pembungaan dan Zat Pemecah Dormansi
}

\section{WAYAN RUMADA ${ }^{1}$, I NYOMAN RAI ${ }^{2 *}$, DAN RINDANG DWIYANI ${ }^{2}$}

\author{
${ }^{1}$ Prodi Magister Pertanian Lahan Kering, Fakultas pertanian, Univ. Udayana, Denpasar \\ ${ }^{2}$ Prodi Agroekoteknologi, Fakultas Pertanian, Univ. Udayana, Denpasar
}

${ }^{*}$ E-mail: rainyoman@unud.ac.id

\begin{abstract}
Fertilization outside the season of Siam Orange (Citrus microcarpa L.) with Induction of Flowering and Dormancy Breaking Substances. The Siam orange (Citrus microcarpa L.) produces seasonal fruit with the on-season harvest from July to August while the off-season harvest, i.e. from February to September there is hardly any fruit, or very limited supply. The purpose of this study was to examine the response of flowering induction and dormancy-breaking substances to produce off-season fruits of Siam orange. This research began in April to December 2016. The experiment was arranged factorially with two factors using a randomized block design (RBD), with nine combination treatments and six replications. Flowering induction factors consist of three levels, namely $\mathrm{I}_{\mathrm{k}}=$ Control, $\mathrm{I}_{\mathrm{P}}=$ Paclobutrazol at a dose of $7.5 \mathrm{~g} / \mathrm{l}$, and $\mathrm{I}_{\mathrm{m}}=$ cutting the tip of dormant twigs. Dormancybreaking substances factor consists of three levels, namely $D_{k}=$ Control, $D_{b}=$ BAP 200 ppm, and $\mathrm{D}_{\mathrm{n}}=\mathrm{KNO}_{3} 300 \mathrm{ppm}$. The results of the experiment showed that the highest fruit weight per tree at off-season production was obtained by induction with paklobutrazol $(28.86 \mathrm{~kg})$ and the lowest was in control $(12.75 \mathrm{~kg})$. Flowering induction treatments was not significantly different effect on fruit quality of Siam orange, represented by weight per fruits, fruit diemater, total soluble solid and vitamine $\mathrm{C}$ content was not siginificant different among levels of treatment. Dormancy-breaking substances treatment also not significantly effect on fruit quality of Siam orange. Based on this research it is recommended to induce flower for off-season produce of Siam orange by pruning the tips of dormant twigs or by using paklobutrzol.
\end{abstract}

Keywords: dormancy-breaking substance, flowering induction, off-season, Siam orange

\section{PENDAHULUAN}

Jeruk Siam merupakan tanaman

buah-buahan tahunan yang sangat potensial di Indonesia, setiap tahunnya mengalami perkembangan dalam pembudidayaan, baik luasan lahan maupun jumlah 
I WAYAN RUMADA et al. Pembuahan Jeruk Siam (Citrus microcarpa L.) di Luar...

produksinya (Balitjestro, 2012). Pariode panen jeruk Siam umumnya terjadi pada Pebruari hingga September dengan puncaknya pada Juni-Agustus (Harjadi et al., 2013). Pola panen demikian menyebabkan ketersediaan jeruk Siam belum dapat memenuhi kebutuhan pasar sepanjang tahun sehingga membuka peluang masuknya jeruk impor ke Indonesia. Peningkatan impor yang signifikan menjadi tantangan tersendiri bagi produsen jeruk nasional. Untuk mendukung peningkatan produktivitas dan permintaan pasar yang memadai, diperlukan teknik budidaya secara efektif dan pemeliharaan kebun yang optimal dengan menerapkan teknologi budidaya yang baik dan benar antara lain melalui pemupukan, pemangkasan, pengaturan pembungan dan penjarangan buah (Balitjestro, 2012).

Sifat musiman menyebabkan ketersediaan buah jeruk Siam melimpah pada musim panen dan tidak ada suplai saat tidak musimnya, sehingga kesinambungan pemasaran menjadi terganggu. Pengembangan teknologi produksi di luar musim penting karena di Indonesia sebagian besar buah di panen secara musiman, musim panen umumnya sangat singkat hanya sekitar 2-3 bulan dan pada saat tersebut harga jual murah.
Pengembangan teknologi produksi buah di luar musim dimaksudkan agar tidak semua pohon berbuah pada saat yang bersamaan (Rai et al., 2016).

Teknologi produksi jeruk Siam di luar musim dapat dilakukan dengan cara merekayasa beberapa faktor yang mempengaruhi pertumbuhan dan perkembangan tanaman menggunakan zat kimia dan/atau perlakuan fisik. Cara kimia dalam teknologi produksi buah di luar musim adalah menggunakan zat-zat yang bersifat penghambat pertumbuhan vegetatif tetapi merangsang pembungaan, contohnya paclobutrazol (Gollagi et al., 2019), daminozide, cycocel dan morphactin. Paclobutrazol dapat mengiduksi pembungaan tetapi tidak memacu perkembangan dan pemunculan bunga (Voon et al., 1992; Gollagi et al., 2019), sehingga penggunaannya perlu dikombinasikan dengan zat pemecah dormansi tunas bunga seperti Benzil Amino Purine (BAP), kalium nitrat $\left(\mathrm{KNO}_{3}\right)$ dan ethephon (Lizawati, 2008). Penggunaan zat pemecah dormansi $\mathrm{KNO}_{3}$ diharapkan dapat memacu pemunculan bunga bagi pucuk yang bunganya sudah terinduksi oleh pemberian zat penginduksi bunga (Astiari et al., 2018). 
Induksi pembungaan dapat pula dilakukan dengan cara fisik atau mekanik, misalnya dengan strangulasi (pelilitan batang, cabang atau ranting), pemangkasan (Budiarto et al., 2018) dan cekaman air (Koshita \& Takahara, 2004). Teknik tersebut ditujukan untuk meningkatkan nisbah $\mathrm{C} / \mathrm{N}$ pada pucuk atau perbandingan unsur carbon (C) dan nitrogen (N). Perlakuan yang dapat meningkatkan nisbah $\mathrm{C} / \mathrm{N}$ akan menyebabkan bunga lebih mudah terinduksi, karena nisbah $\mathrm{C} / \mathrm{N}$ yang tinggi mengakibatkan penumpukan karbohidrat di pucuk yang pada akhirnya akan merangsang pembentukan bunga dan buah (Rai et al., 2004; Koshita \& Takahara, 2004).

Penelitian ini bertujuan untuk mempelajari pembuahan jeruk Siam di luar musim dengan perlakuan induksi pembungaan dan pemberian zat pemecah dormansi.

\section{BAHAN DAN METODE}

Penelitian dilaksanakan di Banjar Seming, Desa Kerta, Kecamatan Payangan, Kabupaten Gianyar, Bali, dari AprilDesember 2017 yaitu pada periode pembuahan di luar musim, menggunakan jeruk Siam yang berumur 5 tahun.
Bahan penelitian yang digunakan adalah pohon jeruk Siam, pupuk kandang, air, paklobutrazol, pestisida, BAP, $\mathrm{KNO}_{3}$, dan bahan-bahan larutan kimia untuk analisis di labolatorium, sedangkan peralatan yang digunakan antara lain Chlorophyll Meter (SPAD-502) Minolta, alat tulis, meteran, pompa air, selang air, timbangan top loader, oven pengering, leaf area meter, gunting pangkas, dan cangkul.

Penelitian menggunakan Rancangan Acak Kelompok (RAK) faktorial 2 faktor. Faktor pertama, perlakuan induksi bunga terdiri atas 3 taraf, yaitu: $\mathrm{I}_{\mathrm{k}}=$ kontrol $\mathrm{I}_{\mathrm{P}}=$ paklobutrazol dengan dosis 7,5 g/l, dan $\mathrm{I}_{\mathrm{m}}$ = pemangkasan ujung pucuk/toping ranting dorman. Faktor kedua, pemberian zat pemecah dormansi tunas terdiri atas 3 taraf, yaitu: $\mathrm{D}_{\mathrm{k}}=$ kontrol, $\mathrm{D}_{\mathrm{b}}=$ BAP $200 \mathrm{ppm}$, dan $\mathrm{D}_{\mathrm{n}}=\mathrm{KNO}_{3} 300$ ppm. Dengan demikian terdapat 9 perlakuan kombinasi dan diulang 6 kali sehingga diperlukan 54 pohon jeruk Siam.

Paklobutrazol diberikan pada april dengan cara melarutkan 7,5 g paklobutrazol dalam 1 liter air kemudian volume 1 liter tersebut disiramkan secara merata di sekitar pangkal pohon jeruk (soil drenching). Pemangkasan pucuk ranting dorman juga dilakukan pada awal penelitian, dilaksanakan pada pohon yang mendapat 
I WAYAN RUMADA et al. Pembuahan Jeruk Siam (Citrus microcarpa L.) di Luar...

perlakuan tersebut, dikerjakan dengan cara memotong seluruh ujung-ujung ranting dorman (toping) pada jarak 7-10 $\mathrm{cm}$ dari ujung ranting menggunakan gunting pangkas. Pemberian BAP dan $\mathrm{KNO}_{3}$ dilakukan satu bulan setelah pemberian paklobutrazol dan pemangkasan ranting, dengan cara menyemprotkan ke pucuk secara merata dengan volume 1 1/pohon.

Variabel yang diamati meliputi jumlah tunas baru per pohon, Kandungan Air Relatif (KAR) daun, kandungan klorofil daun, jumlah bunga per pohon, jumlah buah per pohon, diameter buah, berat per buah, berat buah per pohon, total gula daun, gula reduksi daun, total padatan berlarut, dan kandungan vitamin $\mathrm{C}$ buah.

Jumlah tunas baru per pohon dihitung secara kumulatif sampai akhir penelitian, KAR daun dihitung menurut metode Rai et al. (2016), kandungan klorofil daun diukur dengan alat Chlorophyll Meter SPAD-502, jumlah bunga dan jumlah buah dihitung secara kumulatif pada akhir penelitian, berat per buah diukur dengan mengambil sampel buah secara acak kemudian beratnya ditimbang, lalu berat per buah diperoleh dengan cara membagi berat buah tersebut dengan jumlah buah yang ditimbang. Total gula daun dianalisis menggunakan metode Anthrone sedangkan gula reduksi (R-sugar) mengunakan metode Nelson Somogyi. Total padatan terlarut daging buah diukur menggunakan Hand Reftractometer, dan kadar vitamin $\mathrm{C}$ diukur menurut metode Sudarmadji et al. (1996)

Data dianalisis dengan sidik ragam sesuai rancangan yang digunakan. Apabila interaksi berpengaruh nyata maka dilanjutkan dengan uji Duncan taraf 5\%, sedangkan apabila interaksi berpengaruh tidak nyata maka perbedaan taraf faktor tunggal diuji dengan BNT taraf 5\%.

\section{HASIL DAN PEMBAHASAN}

Hasil analisis statistik menunjukkan intrekasi antara perlakuan induksi pembungaan dan zat pemecah dormansi berpengaruh nyata hanya terhadap variabel gula total dan gula reduksi. Induksi pembungaan berpengaruh nyata terhadap jumlah buah per pohon, berat per buah, gula reduksi, jumlah bunga pertanaman, dan diameter buah. Perlakuan zat pemecah dormansi tunas hanya berpengaruh nyata terhadap jumlah tunas baru per tanaman.

Pada perlakuan induksi pembungaan, berat buah per pohon pada produksi di luar musim tertinggi diperoleh pada induksi dengan paklobutrazol yaitu $28,86 \mathrm{~kg}$ diikuti oleh pemangkasan ujung ranting dengan berat buah per pohon $23,73 \mathrm{~kg}$ dan terendah 
pada kontrol dengan berat buah per pohon hanya $12,75 \mathrm{~kg}$. Antara induksi dengan paklobutrazol dan pemangkasan ujung ranting, berat buah per pohon yang dihasilkan berbeda tidak nyata, yang menunjukkan bahwa kedua taraf perlakuan tersebut secara statistik sama efektifnya. Tingginya berat buah per pohon pada induksi dengan paklobutrazol dan pemangkasan ujung ranting didukung oleh jumlah buah per pohon pada taraf tersebut yang nyata lebih tinggi dibandingkan kontrol (Tabel 1) serta berat per buah yang cendrung lebih tinggi (Tabel 2). Jumlah buah per pohon pada induksi dengan paklobutrazol dan pemangkasan ujung ranting yang lebih tinggi dari kontrol disebabkan oleh jumlah bunga per pohon tertinggi dihasilkan pada induksi dengan paklobutrazol yaitu 324,00 bunga per pohon, sedangkan terendah pada kontrol dengan jumlah bunga terbentuk hanya 130,83 bunga per pohon. Jumlah bunga terbentuk pada induksi dengan paklobutrazol berbeda tidak nyata dengan pemangkasan ranting dengan jumlah bunga yang dihasilkan taitu 282,00 bunga per pohon (Tabel 1). Hasil penelitian ini sesuai dengan Yulianto et al. (2008), bahwa perangsangan pembungaan dengan paklobutrazol dan pemangkasan pada kelengkeng mampu meningkatkan jumlah pohon berbunga serta meningkatkan kerapatan bunga dan buah per pohon. Berat buah dan jumlah buah per pohon yang lebih tinggi pada induksi pembungaan dengan paklobutrzol dan pemangkasan ujung ranting pada penelitian ini diduga berkaitan dengan kandungan klorofil yang lebih tinggi pada kedua taraf perlakuan tersebut dibandingkan kontrol. Pada Tabel 1 dapat dilihat, kandungan klorofil pada induksi dengan paklobutrazol dan pemangkasan ujung ranting masing-masing 67,26 SPAD dan 67,10 SPAD sedangkan pada kontrol hanya 67,10 SPAD. Kandungan klotofil yang relatif lebih tinggi akan memberikan proses fotosintesis lebih baik sehingga fotosintat yang dihasilkan leboh tinggi untuk dialokasikan ke buah. Menurut Sharma et al. (1994), fotosintat yang dihasilkan oleh tanaman sebagian akan digunakan untuk mendukung perkembangan vegetatif dan sebagian digunakan untuk pertumbuhan generatif sehingga perkembangan bunga dan buah cendrung meningkat.

Berbeda dengan berat dan jumlah buah per pohon yang tertinggi pada paklobutrazol, jumlah tunas baru per pohon malah terrendah pada paklobutrazol. Tabel 1 menunjukkan jumlah tunas baru per 
I WAYAN RUMADA et al. Pembuahan Jeruk Siam (Citrus microcarpa L.) di Luar...

pohon pada induksi paklbotrazol sebesar 126,77 buah, nyata lebih rendah dibandingkan kontrol (179,44 buah) dan pemangkasan ujung ranting (173,16 buah).

Rendahnya jumlah tunas baru pada pemberian paklobutrazol sesuai dengan penelitian Rai et al. (2004) bahwa manggis yang diinduksi dengan paklobutrazol pertumbuhan vegetatifnya menurun ditunjukkan oleh jumlah tunas baru menurun nyata diikuti dengan pemendekan ruas pada pucuk baru.

Tabel 1. Pengaruh induksi pembungaan dan zat pemecah dormansi terhadap jumlah tunas baru per pohon, jumlah bunga dan jumlah buah per pohon, kandungan krolofil daun, kandungan ari relative daun, dan berat buah per pohon.

\begin{tabular}{|c|c|c|c|c|c|c|}
\hline Perlakuan & $\begin{array}{l}\text { Jumlah } \\
\text { tunas baru } \\
\text { per pohon } \\
\text { (buah) }\end{array}$ & $\begin{array}{l}\text { Jumlah } \\
\text { bunga per } \\
\text { pohon } \\
\text { (buah) }\end{array}$ & $\begin{array}{l}\text { Jumlah } \\
\text { buah per } \\
\text { pohon } \\
\text { (buah) }\end{array}$ & $\begin{array}{c}\text { Kandungan } \\
\text { krolofil } \\
\text { daun } \\
\text { (SPAD) }\end{array}$ & $\begin{array}{c}\text { Kandungan } \\
\text { air relatif } \\
\text { daun }(\%)\end{array}$ & $\begin{array}{c}\text { Berat } \\
\text { buah per } \\
\text { pohon } \\
(\mathrm{kg})\end{array}$ \\
\hline \multicolumn{7}{|c|}{ Induksi Pembungaan (I) } \\
\hline $\mathrm{I}_{\mathrm{k}}$ & $179,44 \mathrm{a}$ & $130,83 \mathrm{~b}$ & $110,05 \mathrm{~b}$ & $67,06 \mathrm{a}$ & $72,48 \mathrm{a}$ & $12,75 \mathrm{~b}$ \\
\hline $\mathrm{I}_{\mathrm{p}}$ & $126,77 \mathrm{~b}$ & $324,00 \mathrm{a}$ & $238,50 \mathrm{a}$ & 67,26 a & $72,23 b$ & 28,86 a \\
\hline $\mathrm{I}_{\mathrm{m}}$ & $173,16 \mathrm{a}$ & $282,00 \mathrm{a}$ & $143,72 \mathrm{~b}$ & $67,10 \mathrm{a}$ & $72,43 \mathrm{ab}$ & $23,73 \mathrm{a}$ \\
\hline BNT 5\% & 33,65 & 49,66 & 73,12 & 1,94 & 0,15 & 4,13 \\
\hline \multicolumn{7}{|c|}{ Pemecah Dormansi (D) } \\
\hline $\mathrm{D}_{\mathrm{k}}$ & $130,77 \mathrm{~b}$ & $154,94 \mathrm{a}$ & $140,66 \mathrm{a}$ & $66,79 \mathrm{a}$ & $72,34 \mathrm{a}$ & $25,16 \mathrm{a}$ \\
\hline $\mathrm{D}_{\mathbf{b}}$ & $187,29 \mathrm{a}$ & 177,77 a & $163,88 \mathrm{a}$ & 65,76 a & $72,59 \mathrm{a}$ & $26,50 \mathrm{a}$ \\
\hline$D_{n}$ & $160,16 \mathrm{ab}$ & $141,11 \mathrm{a}$ & $126,72 \mathrm{a}$ & 68,16 a & 72,19 a & $22,70 \mathrm{a}$ \\
\hline BNT 5\% & 33,65 & 45,66 & 73,12 & 1,94 & 0,15 & 4,13 \\
\hline
\end{tabular}

Keterangan: angka-angka pada kolom sama yang diikuti doleh huruf sama berbeda tidak nyata berdasarkan uji BNT 5\% 
Tabel 2. Pengaruh induksi pembungaan dan zat pemecah dormansi tunas terhadap berat per buah, diameter buah, kandungan air buah, dan buah gugur

\begin{tabular}{cccccc}
\hline Perlakuan & $\begin{array}{c}\text { Berat per } \\
\text { buah }(\mathrm{g})\end{array}$ & $\begin{array}{c}\text { Diameter } \\
\text { buah }(\mathrm{cm})\end{array}$ & $\begin{array}{c}\text { Buah gugur } \\
(\mathrm{buah})\end{array}$ & $\begin{array}{c}\text { Total padatan } \\
\text { terlarut TPT }(\%)\end{array}$ & $\begin{array}{c}\text { Vitamin C } \\
(\mathrm{mg} / 100 \mathrm{~g})\end{array}$ \\
\hline Induksi Pembungaan $(\mathbf{I})$ & & & & \\
\hline $\mathrm{I}_{\mathrm{k}}$ & $186,5 \mathrm{a}$ & $6,02 \mathrm{a}$ & $20,45 \mathrm{a}$ & $6,80 \mathrm{a}$ & $1,16 \mathrm{a}$ \\
$\mathrm{I}_{\mathrm{p}}$ & $187,94 \mathrm{a}$ & $6,78 \mathrm{a}$ & $15,13 \mathrm{a}$ & $6,66 \mathrm{a}$ & $1,34 \mathrm{a}$ \\
$\mathrm{I}_{\mathrm{m}}$ & $192,33 \mathrm{a}$ & $6,92 \mathrm{a}$ & $16,39 \mathrm{a}$ & $6,80 \mathrm{a}$ & $1,21 \mathrm{a}$ \\
\hline BNT 5\% & 22,40 & 4,58 & 8,19 & 0,30 & 0,24 \\
\hline Pemecah Dormansi (D) & & & & \\
\hline $\mathrm{D}_{\mathrm{k}}$ & $196,22 \mathrm{a}$ & $6,47 \mathrm{a}$ & $19,17 \mathrm{a}$ & $6,75 \mathrm{a}$ & $1,15 \mathrm{a}$ \\
$\mathrm{D}_{\mathrm{b}}$ & $188,22 \mathrm{a}$ & $6,61 \mathrm{a}$ & $16,95 \mathrm{a}$ & $6,83 \mathrm{a}$ & $1,32 \mathrm{a}$ \\
$\mathrm{D}_{\mathrm{n}}$ & $182,33 \mathrm{a}$ & $6,64 \mathrm{a}$ & $15,85 \mathrm{a}$ & $6,69 \mathrm{a}$ & $1,24 \mathrm{a}$ \\
\hline BNT 5\% & 22,40 & 4,58 & 8,19 & 0,30 & 0,24 \\
\hline
\end{tabular}

Keterangan: angka-angka pada kolom sama yang diikuti doleh huruf sama berbeda tidak nyata berdasarkan uji BNT 5\%

Menurut Voon et al. (1992) dan Gollagi et al. (2019), bahwa paklobutrzol adalah growth retardant yang bersifat sebagai anti-geberelin sehingga menghambat perpanjangan sel. Terhambatnya perpanjangan sel menyebabkan terhambatnya pertumbuhan tunas baru. Menurut Darmawan (2014), kandungan giberelin yang tinggi pada pohon buah-buahan seperti jeruk, mangga, dan manggis akan memacu pertumbuhan vegetatif dan menghambat pembungaan, oleh karena itu dalam penelitian ini pemberian pklobutrazol yang bersifat anti-giberelin maka jumlah tunas baru yang diperoleh menurun nyata. Pada pemangkasan ujung ranting, jumlah tunas baru yang berdeda tidak nyata dibandingkan kontrol menunjukkan bahwa pemangkasan ujung ranting tidak menganggu tumbuhnya tunas baru. Berdasarkan pengamatan secara visual, jeruk Siam yang ujung rantingnya dipangkas (toping), 3-4 minggu setelah pemangkasan akan tumbuh ranting-ranting baru pada ketiak daun dibawah lokasi pemotongan. Ranting-ranting baru tersebut akhirnya menumbuhkan bunga sehingga menyebabkan pemangkasan ujung ranting dapat berfungsi sebagai penginduksi tumbuhnya bunga sehingga jeruk Siam dapat berbuah di luar musim. Kondisi endogen yang menyebabkan kenapa pemangkasan ujung ranting mengakibatkan dengan cepat bisa tumbuh tunas baru dan tunas baru ini kemudian menghasilkan 
I WAYAN RUMADA et al. Pembuahan Jeruk Siam (Citrus microcarpa L.) di Luar...

bunga dan buah perlu diteliti lebih lanjut. Ada dugaan, ranting dorman mengandung senyawa endogen tertentu yang menghambat pembungaan dan tumbuhnya tunas baru, dan begitu ujung ranting dorman tersebut dipangkas maka senayawa endogen tersebut terbuang sehingga hambatan pembungaan teratasi.

Kualitas buah jeruk siam yang diwakili oleh berat per buah, diameter buah, total padatan terlarut dan kandungan vitamin $\mathrm{C}$ berbeda tidak nyata antara pemberian paklobutrazol dengan pemangkasan ujung ranting dan kontrol (Tabel 2). Kualitas buah yang tidak menurun pada induksi dengan paklobutrazol dan pemangkasan ujung ranting menunjukkan bahwa perlakuan tersebut efektif dalam meningkatkan berat dan jumlah buah per pohon jeruk Siam pada pembuahan off-season, tetapi tidak berdampak negatif terhadap kualitas buah yang dihasilkan.

Pada perlakuan zat pemecah dormansi, berat buah dan jumlah buah per pohon serta kualitas buah yang dihasilkan berbeda tidak nyata antara pemberian BAP dan $\mathrm{KNO}_{3}$ dengan kontrol. Perbedaan nyata hanya didapat pada variabel jumlah tunas baru per pohon, dimana pada pemberian BAP dan $\mathrm{KNO}_{3}$ jumlah tunas baru yang dihasilkan masing-masing 187,29 buah dan 160,16 buah sedangkan pada kontrol hanya 130,77 buah (Tabel 1). Tunas baru yang dihasilkan pada perlakuan zat pemecah dormansi BAP nyata lebih tinggi dibandingkan kontrol, tetapi pemangkasan ujung rating berbeda tidak nyata dengan kontrol. Data tersebut menunjukkan bahwa lebih tingginya jumlah tunas baru yang dihasilkan pada $\mathrm{KNO}_{3}$ dan kontrol tidak mempengaruhi hasil dan kualitas hasil. Berat dan jumlah buah per pohon serta kualitas hasil yang berbeda tidak nyata pada perlakuan zat pemecah dormansi berkaitan dengan total gula dan gula reduksi daun. Pada Tabel 3 dapat dilihat, pada tanaman yang bunganya tidak diinduksi $\left(\mathrm{I}_{\mathrm{k}}\right)$, total gula daun tertinggi diperoleh pada kontrol atau tidak diberikan zat pemecah dormansi $(11,61 \%)$ dan nyata lebih tinggi dibandingkan pada tanaman yang diberikan zat pemecah dormansi BAP dan $\mathrm{KNO}_{3}$. Pada induksi dengan paklobutrazol dan pemangkasan ujung ranting, total gula daun antara tanam yang tidak diberikan zat pemecah dormansi dan diberikan zat pemecah dormansi BAP dan $\mathrm{KNO}_{3}$ berbeda tidak nyata. Demikian pula untuk variabel gula reduksi. Pada induksi dengan paklobutrazol dan pemangkasan ujung ranting, gula reduksi daun antara tanam 
yang tidak diberikan zat pemecah dormansi dan diberikan zat pemecah dormansi BAP dan $\mathrm{KNO}_{3}$ juga berbeda tidak nyata (Tabel 3). Dapat dikatakan bahwa proses fotosintesis pada tanaman yang mendapatkan perlakuan zat pemecah dormansi berbeda tidak nyata, dan haltersebut berkaitan dengan beebeda tidak nyatanya kandungan klorofil daun dan kandungan air relative daun antara kontrol dengan pemberian BAP dan $\mathrm{KNO}_{3}$ (Tabel 1). Diduga dalam penelitian ini pemberian BAP dan $\mathrm{KNO}_{3}$ terlambat, dimana saat diberikan pohon jeruk penelitian sudah ada yang berbunga. Hasil penelitian ini sesuai dengan Darmawan (2014) dan Astiari et al. (2018), bahwa penggunaan zat pemecah dormansi tidak berpengaruh terhadap pembungaan serta hasil dan kualitas hasil tanaman jeruk keprok. Susanto \& Poerwanto (1990) menyatakan bahwa perlakuan zat pemecah dormansi tidak berpengaruh terhadap waktu munculnya bunga mangga karena tanaman telah berbunga sebelum diaplikasikan zat pemecah dormansi.

Tabel 3. Interaksi antara faktor induksi pembungaan dengan zat pemecah dormansi tunas terhadap total gula dan gula reduksi daun

\begin{tabular}{ccccccc}
\hline \multirow{2}{*}{ perlakuan } & \multicolumn{3}{c}{ Total gula daun $(\%)$} & \multicolumn{3}{c}{ Gula reduksi daun $(\%)$} \\
\cline { 2 - 7 } & $\mathrm{D}_{\mathrm{k}}$ & $\mathrm{D}_{\mathrm{b}}$ & $\mathrm{D}_{\mathrm{n}}$ & $\mathrm{D}_{\mathrm{k}}$ & $\mathrm{D}_{\mathrm{b}}$ & $\mathrm{D}_{\mathrm{n}}$ \\
\hline $\mathrm{I}_{\mathrm{k}}$ & $11,61 \mathrm{a}$ & $8,00 \mathrm{~b}$ & $9,94 \mathrm{ab}$ & $0,87 \mathrm{c}$ & $1,07 \mathrm{bc}$ & $1,30 \mathrm{ab}$ \\
$\mathrm{I}_{\mathrm{p}}$ & $10,46 \mathrm{ab}$ & $9,95 \mathrm{ab}$ & $9,96 \mathrm{ab}$ & $1,38 \mathrm{a}$ & $1,22 \mathrm{ab}$ & $1,42 \mathrm{a}$ \\
$\mathrm{I}_{\mathrm{m}}$ & $8,50 \mathrm{~b}$ & $9,50 \mathrm{~b}$ & $9,04 \mathrm{~b}$ & $1,35 \mathrm{ab}$ & $1,30 \mathrm{ab}$ & $1,07 \mathrm{bc}$ \\
\hline
\end{tabular}

Keterangan: angka-angka pada kolom yang sama yang diikuti dengan huruf yang sama berpengaruh berbeda tidak nyata berdasarkan uji Duncan.

\section{SIMPULAN}

Berat buah per pohon pada produksi jeruk Siam di luar musim tertinggi diperoleh pada induksi dengan paklobutrazol yaitu 28,86 $\mathrm{kg}$ diikuti oleh pemangkasan ujung ranting $(23,73 \mathrm{~kg})$ dan terendah pada kontrol $(12,75 \mathrm{~kg})$. Perlakuan induksi pembungaan berpengaruh tidak nyata terhadap kualitas buah, yang diwakili oleh berat per buah, diameter buah, total padatan terlarut dan kandungan vitamin $\mathrm{C}$ berbeda tidak nyata antara pemberian paklobutrazol dengan pemangkasan ujung ranting dan kontrol. Perlakuan zat pemecah dormansi berpengaruh tidak nyata terhadap berat buah dan jumlah buah per pohon serta 
I WAYAN RUMADA et al. Pembuahan Jeruk Siam (Citrus microcarpa L.) di Luar...

kualitas buah. Berdasarkan penelitian ini disarankan melakukan induksi pembungaan dengan pemangkasan ujung ranting atau pemberian paklobutrazol. Di samping itu, perlu dilakukan penelitian waktu pemberian zat pemecah dormansi yang tepat dan meningkatkan konsentrasi BAP dan $\mathrm{KNO}_{3}$ untuk memproduksi buah jeruk Siam di luar musim.

\section{DAFTAR PUSTAKA}

Astiari, N. K. A., Kartini, L., Sulistiawati, N. P. A., \& Rai, I. N. (2018). Efforts to produce Siamese citrus fruit out of season and fruit quality improvement through application of potassium nitrate and agrodyke fertilizer. International Journal of Life Sciences, 2(3), 48-58. https://doi.org/10.29332/ijls.v2n3.206

Balitjestro, B. P. T. J. B. S. (2012). Varietas Jeruk Unggulan Nasional. Malang (ID): Balitjestro Berdasarkan Taksonometri.

Budiarto, R., Poerwanto, R., Santosa, E., \& Efendi, D. (2018). Shoot manipulations improve flushing and flowering of Mandarin citrus in Indonesia. Journal of Applied Horticulture, 20(2), 112-118. https://doi.org/10.37855/jah.2018.v20 i02.20

Darmawan, M. (2014). Induksi pembungaan di luar musim pada tanaman jeruk keprok (Citrus reticulata). Sekolah Pasca Sarjana IPB, Bogor.

Gollagi, S., Jasmitha, B., \& Sreekanth, H. (2019). A review on: Paclobutrazol a boon for fruit crop production. Journal of Pharmacognosy and
Phytochemistry, 8(3), 2686-2691.

Harjadi, S. S., Widodo, W. D., \& Suketi, K. (2013). Aspek-aspek penting budidaya buah-buahan. Institut Pertanian Bogor.

Koshita, Y., \& Takahara, T. (2004). Effect of water stress on flower-bud formation and plant hormone content of satsuma mandarin (Citrus unshiu Marc.). Scientia Horticulturae, 99(34), 301-307. https://doi.org/10.1016/S03044238(03)00113-4

Lizawati. (2008). Induksi pembungaan dan pembuahan tanaman buah dengan penggunaan retardan. Jurnal Agronomi, 12(2), 18-22.

Rai, I. N., Poerwanto, R., Darusman, L. K., \& Purwoko, B. S. (2004). Pengaturan Pembungaan Tanaman Manggis (Garcinia mangostana L.) di Luar Musim dengan Strangulasi, serta Aplikasi Paklobutrazol dan Etepon. Jurnal Agronomi Indonesia, 32(2), 12-20. https://doi.org/https://doi.org/10.2483 1/jai.v32i2.1438

Rai, I. N., Semarajaya, C. G. A., Wiraatmaja, I. W., \& Alit Astiari, K. (2016). Relationship between IAA, sugar content and fruit-set in snake fruit (Zalacca salacca). Journal of Applied Horticulture, 18(03), 213216. https://doi.org/10.37855/jah.2016.v18 i03.37

Sharma, P. N., Kumar, N., \& Bisht, S. S. (1994). Effect of zinc deficiency on chlorophyll content, photosynthesis and water relations of cauliflower plants. Photosynthetica, 30(3), 353359.

Sudarmadji, S., Haryono, B., \& Suhardi. (1996). Analisis Bahan Makanan dan Pertanian.

Susanto, S., \& Poerwanto, R. (1990). 
Agrotrop : Journal on Agriculture Science, 11 (1): 10 - 20 (2021)

Pengaruh Paclobutrazol dan Hidrogen Sianida terhadap pertumbuhan dan pembungaan tanaman mangga arumanis. Jurnal Agronomi Indonesia, 27(2), 22-29.

Voon, C. H., Rowley, A. J., Hongsbhanich, N., \& Pitakpaivan, C. (1992). Cultar* development in tropical fruits - an overview. Acta Horticulturae, 321, 270-281.

https://doi.org/10.17660/ActaHortic.1 992.321.27

Yulianto, Susilo, J., \& Juanda, D. (2008). Keefektifan Teknik Perangsangan Pembungaan pada Kelengkeng. Jurnal Hortikultura, 18(2), 148-154. 